\title{
Identifying the predisposing factors, signs and symptoms of overreaching and overtraining in physical education professionals
}

\author{
Ricardo B. Viana ${ }^{1}$, Paulo Gentil ${ }^{1}$, Vinício S. Lorenço ${ }^{1}$, Carlos A. Vieira ${ }^{1}$, Mário H. Campos ${ }^{1}$, Douglas A.T. \\ Santos $^{1,2}$, Wellington F. Silva ${ }^{1}$, Marilia S. Andrade ${ }^{3}$, Rodrigo L. Vancini ${ }^{4}$, Claudio A. B. de Lira ${ }^{\text {Corresp. } 1}$ \\ 1 Faculdade de Educação Física e Dança, Universidade Federal de Goiás, Goiânia, Goiás, Brazil \\ 2 Colegiado de Educação Física, Universidade do Estado da Bahia, Teixeira de Freitas, Bahia, Brazil \\ 3 Departamento de Fisiologia, Universidade Federal de São Paulo, São Paulo, São Paulo, Brazil \\ 4 Centro de Educação Física e Desportos, Universidade Federal do Espírito Santo, Vitória, Espírito Santo, Brazil \\ Corresponding Author: Claudio A. B. de Lira \\ Email address: andre.claudio@gmail.com
}

Background: It is possible that physical education professionals, especially those who participate in aerobic activities, have predisposing factors, signs and symptoms of overreaching (OVR) and overtraining (OVT) due to a high load and volume of exercise followed by suboptimal recovery time. The present study aimed to identify the predisposing factors, signs and symptoms of OVR and OVT in physical education professionals.

Methods: A questionnaire consisting of 42 questions (10 questions group) about predisposing factors and signs/symptoms was answered by 132 physical education professionals from both sexes (83 men and 49 women) who were allocated into a resistance training group ( $R G, n=74)$, aerobic training group ( $A G, n=$ 20 ) and resistance and aerobic training group ( $R A G, n=38$ ). A mean score was calculated ranging from 1 (completely absent) to 5 (severe) for each question group. A low occurrence of predisposing factors and signs and symptoms of OVR and OVT was considered to be a question group score 4 or lower. Profile of Mood State Questionnaire (POMS) was also applied.

Results: A mean score of $2.5 \pm 0.7,2.7 \pm 0.7$ and $2.7 \pm 0.8$ was found for all question groups for RG, AG and RAG, respectively. Of the total sample, $40.6 \%$ trained at least 5 times/week. The POMS revealed that $67.5 \%$ of the RG ( $n=50), 80 \%$ of the AG $(n=16)$ and $60.5 \%$ of the RAG $(n=23)$ were classified as having no mood disorders and a standard graphic iceberg was presented. There were no statistical differences $(p>0.05)$ in the total mood disorders among RG (13.9 \pm 24.5$)$, AG (10.3 \pm 25.1$)$ and RAG (14.6 \pm 27.9$)$ groups.

Conclusion: Despite the volume of training/body working performed by the physical education professionals surveyed being greater than the recommended to achieve improvements on physical fitness, they did not show predisposing factors, signs or symptoms of OVR and OVT. 
1 Original Article

2

3 Identifying the predisposing factors, signs and symptoms of overreaching and overtraining 4 in physical education professionals

6 Running head: Overtraining and physical education professionals

8 Ricardo B. Viana ${ }^{1}$, Paulo Gentil ${ }^{1}$, Vinício S. Lorenço ${ }^{1}$, Carlos A. Vieira ${ }^{1}$, Mário H. Campos ${ }^{1}$,

9 Douglas A.T. Santos ${ }^{1,2}$, Wellington F. Silva ${ }^{1}$, Marília S. Andrade ${ }^{3}$, Rodrigo L. Vancini ${ }^{4}$, Claudio 10 A.B. de Lira ${ }^{1 *}$

11

$12{ }^{1}$ Faculdade de Educação Física e Dança, Universidade Federal de Goiás, Goiânia, Goiás, Brazil

13 1,2 Colegiado de Educação Física, Universidade do Estado da Bahia, Teixeira de Freitas, Brazil

$14{ }^{3}$ Departamento de Fisiologia, Universidade Federal de São Paulo, São Paulo, Brazil

$15{ }^{4}$ Centro de Educação Física e Desportos, Universidade Federal do Espírito Santo, Vitória, 16 Espírito Santo, Brazil

\section{8 *Corresponding Author:}

19 Claudio Andre Barbosa de Lira

20 Email address: andre.claudio@gmail.com 


\section{ABSTRACT}

23 Background: It is possible that physical education professionals, especially those who 24 participate in aerobic activities, have predisposing factors, signs and symptoms of overreaching 25 (OVR) and overtraining (OVT) due to a high load and volume of exercise followed by suboptimal recovery time. The present study aimed to identify the predisposing factors, signs and symptoms of OVR and OVT in physical education professionals.

Methods: A questionnaire consisting of 42 questions (10 questions group) about predisposing factors and signs/symptoms was answered by 132 physical education professionals from both sexes (83 men and 49 women) who were allocated into a resistance training group $(R G, n=74)$, aerobic training group $(\mathrm{AG}, \mathrm{n}=20)$ and resistance and aerobic training group $(\mathrm{RAG}, \mathrm{n}=38)$. A mean score was calculated ranging from 1 (completely absent) to 5 (severe) for each question group. A low occurrence of predisposing factors and signs and symptoms of OVR and OVT was considered to be a question group score 4 or lower. Profile of Mood State Questionnaire (POMS) was also applied.

Results: A mean score of $2.5 \pm 0.7,2.7 \pm 0.7$ and $2.7 \pm 0.8$ was found for all question groups for $\mathrm{RG}, \mathrm{AG}$ and RAG, respectively. Of the total sample, $40.6 \%$ trained at least 5 times/week. The POMS revealed that $67.5 \%$ of the RG $(n=50), 80 \%$ of the $A G(n=16)$ and $60.5 \%$ of the RAG ( $\mathrm{n}=23$ ) were classified as having no mood disorders and a standard graphic iceberg was presented. There were no statistical differences $(\mathrm{p}>0.05)$ in the total mood disorders among RG

$41(13.9 \pm 24.5), \mathrm{AG}(10.3 \pm 25.1)$ and RAG (14.6 \pm 27.9$)$ groups.

42 Conclusion: Despite the volume of training/body working performed by the physical education professionals surveyed being greater than the recommended to achieve improvements on physical fitness, they did not show predisposing factors, signs or symptoms of OVR and OVT. 


\section{INTRODUCTION}

Overtraining syndrome (OVT) is characterized by multiple signs and symptoms. It involves the accumulation of stress, leading to a decrease in physical/mental/working performance during the sports season (Budgett, 1990). OVT is commonly attributed to an imbalance between training/working stimulus [generally, aerobic training (Elliott, Wagner \& Chiu, 2007)] and rest periods, therefore, the individual is subjected to high intensity and/or high volumes without an appropriate recovery time (Lemyre, Roberts \& Stray-Gundersen, 2007; Jones \& Tenenbaum, 2009; Meeusen et al., 2013). Psychological and/or social stressors can also contribute to this syndrome (Kreher \& Schwartz, 2012). Apart from a decrease in performance, OVT syndrome is usually accompanied by physiological, immunological, biochemical and psychological alterations (Fry, Morton \& Keast, 1991; Lehmann, Foster \& Keul, 1993; Kuipers, 1998; Carfagno \& Hendrix, 2014). For example, the following alterations are common in OVT: parasympathetic (fatigue, depression, bradycardia and loss of motivation), sympathetic (insomnia, irritability, tachycardia, agitation, hypertension and restlessness) and others (anorexia, weight loss, lack of concentration, anxiety, heavy/stiff muscle, and awakening unrefreshed) (Carfagno \& Hendrix, 2014).

During some periods of the sports season, such as a shock microcycle, coaches can plan an intentional increase in volume/intensity of training load in order to potentiate physiological adaptations that would result in a chronic increase of performance (Issurin, 2010). Frequently, this training manipulation leads the athlete to develop transitory signs and symptoms similar to OVT syndrome known as overreaching (OVR) (Fry, Morton \& Keast, 1991; Lehmann, Foster \& Keul, 1993; Kuipers, 1998). However, OVR recovery can occur a few days after refraining from training or decreasing exercise volume/intensity. Conversely, OVT can last for weeks or months and might even lead to the interruption of an athlete's carrer (Ackel-D'Elia et al., 2010).

At least in Brazil, many physical education professionals work in gyms and exercise facilities and centers (da Silva, Santos \& Araújo, 2016). According to Brazilian legislation (Brazil, 1998), the physical education professionals are responsible for exercise prescription in these workplaces. It is reasonable to assume that these professionals present a high level of physical exertion, constituted by physical exercise performed in working environment (e.g.: during group-based activities) added to their own training routine. In addition, these professionals may be exposed to other external factors to the training, such as family, economic, 
76 social and emotional problems, which may further predispose to symptoms of OVR and/or OVT 77 syndrome (Hjälm et al., 2007; Fletcher \& Scott, 2010; Mazerolle et al., 2011).

Thus, it is possible that this specific population has predisposing factors, signs and symptoms of OVR and OVT due to a high load and volume of exercise followed by suboptimal recovery time. Therefore, this study aimed to identify the predisposing factors, signs and symptoms of OVR and OVT in physical education professionals. We hypothesized that physical education professionals who work in gyms/exercise facilities have a high load and volume of exercise accompanied by inappropriate recovery. This might be especially true for professionals who participate in aerobic activities, which could potentiate OVT syndrome. Thus, these professionals could present predisposing factors, signs and symptoms of OVR and OVT.

\section{MATERIALS AND METHODS}

\section{Sample}

A power analysis based on a medium effect size $(d=0.30)$ for the interaction between groups $>$ of 0.05 indicated that a sample size of 126 participants provides a statistical power of 0.85 (Faul et al., 2009). Based on this, the present study involved a total of 132 volunteers (83 men and 49 women). The professionals were recruited from 13 gyms located in Goiânia (Brazil) and enrolled in the study based on the following criteria: i) performing at least one daily exercise session not shorter than $60 \mathrm{~min}$, with a minimum frequency of 4 days/week (total of 4 hours/week); ii) aged between 18 and 35 years; and iii) all kinds of physical exercise were acceptable (Ackel-D'Elia et al., 2010). The selected volunteers were classified into three groups: resistance training group ( $R G)(n=74 ; 50$ men and 24 women), composed of physical education professionals who work and practice only in resistance training (this group served as control); aerobic training group (AG) $(n=20 ; 10$ men and 10 women), composed of physical education professionals who work and practice only in aerobic training (running, fitness classes and others.); and resistance and aerobic training group (RAG) $(\mathrm{n}=38 ; 23$ men and 15 women), composed of physical education professionals who work and practice both resistance and aerobic training (Table 1). 


\section{Experimental design and variables analyzed}

106

107

108

110

111

112

113

114

115

116

117

118

119

120

121

122

123

124

125

126

127

128

129

130

131

132

133

134

135

A cross-sectional study was conducted with the application of two questionnaires. The first questionnaire, adapted from Ackel-D'Elia et al. (2010), aims to identify predisposing factors, signs and symptoms of OVR and OVT, and the other questionnaire, the Profile of Mood State Questionnaire (POMS), aims to identify mood disorders in the volunteers (McNair, Lorr \& Droppleman, 1971).

Briefly, the first questionnaire aims to identify predisposing factors, signs and symptoms of OVR and OVT. It consists of 42 questions related to the work activity and/or study, obligations and external problems to training, type of physical activity practiced, motivation for class/training, patterns of rest and recovery, nutritional factors, presence of chronic diseases, medication use, monotony, fatigue and motivation, self-evaluation of training/class, performance and recovery, sleep quality, injury incidence, appetite changes, weight loss, frequency of upper respiratory tract infections and excessive sweating, volume of training/class and time of physical activity practiced. The questions were classified into 10 groups of questions related to either predisposing factors (question groups 1 to 6) or signs and symptoms (question groups 7 to 10 ).

The scores of the question groups were calculated as performed by Ackel-D'Elia et al. (2010):

Each volunteer was asked to make a self-assessment for each question using a fivepoint scale. The scale ranged from 1 (absence) to 5 (severe). Mean score (MS) for each question was calculated according to the expression: $M S=\sum(f x S)_{n}$, where $f$ stands for the ratio between the frequency of the response for the number of alternatives and the total frequency (\%) obtained for each alternative within a question, S stands for the score attributed to each alternative within a question, and $n$ stands for the number of alternatives for each question. The final MS for a specific question group was calculated as the mean of each individual MS obtained for the selected questions fitted to a specific question group. [...] The individual MS for the three features was computed using the same formula as described above, and the final group MS was calculated as the mean of the three individual mean scores. 
The volunteer was considered with OVR/OVT when scoring higher than 4 in at least 6 of

137 the 10 question groups and presented an altered mood state profile. Table 2 shows the group of

138 questions used in the identification of predisposing factors, signs and symptoms of OVR and

139 OVT. This questionnaire was designed based on a broad literature review about OVT and OVR

140 and its design and validation was based on the guidelines outlined by Juniper, Guyatt \& Jaeschke

141 (1995).

142 The self-evaluation of training, performance and recovery were evaluated by means of 143 questions 9 (How do you assess your exercise session?), 10 (How do you evaluate your physical 144 performance?), and 11 (How do you evaluate your physical recovery after training sessions?), 145 respectively. For this, we used a modified Borg scale. For question 9, the possible answers were 146 'very, very light', 'very light', 'slightly light', 'a little heavy', 'heavy', 'too heavy', and 'very, 147 very heavy'. For question 10, the possible answers were 'very, very bad', 'very bad', 'poor', 148 'average', 'good', 'very good', and 'very, very good'. For question 11, the possible answers were 149 'very, very poor', 'poor', 'reasonable', 'good', 'very good', and very, very good'. This strategy 150 was previously by other studies to assess breathlessness (for review, see Bausewein et al., 2007).

151 For the purposes of this study, high-intensity exercise was when the participant answered 152 'heavy'; 'too heavy', or 'very, very heavy' in question 9. Participants were considered to have a 153 decrease in performance if: 1) they were located at the far right of the frequency distribution in at 154 least two of questions 9, 10, and 11; or 2) answered 'heavy', 'too heavy', or 'very, very hard' to 155 question 9; or 3) who answered 'bad', 'very bad', or 'very, very bad' to question 10 and 'poor', 'very poor', and 'very, very poor' to question 11.

157 The second questionnaire used, POMS, aimed to identify mood disorders in the 158 volunteers. The POMS consists of 65 adjectives that are related to mood, using a scale from 0 to 159 4, where '0 - no way', 1 - a little, '2 - moderately', '3 - enough', and '4 - very much'. This 160 instrument evaluates six categories: tension-anxiety, depression-dejection, anger-hostility, 161 vigour-activity, fatigue-inertia, and mental confusion-bewilderment (McNair, Lorr \& 162 Droppleman, 1971; Spreen \& Strauss, 1998).

163 The scores of the POMS were calculated by adding the negative factors (tension, 164 depression, anger, fatigue, and confusion) and subtracting the positive (vigour). Additionally, it 165 was analyzed whether the volunteer has or not a positive iceberg profile. A positive iceberg 166 profile indicates that the volunteer does not have mood disorders and is characterized by a low 
167 tension, depression, anger, fatigue and confusion score and a high vigour score. When the scores

168 related to stress, depression, anger, fatigue and confusion are high and the vigour score is low the 169 result is a so-called inverted (negative) iceberg profile, featuring a state of altered mood 170 (McNair, Lorr \& Droppleman, 1971; Morgan et al., 1987). The POMS questionnaire is widely 171 utilized because of its feasibility, reliability, and validity common use in psychometric studies 172 (Morgan et al., 1988; McNair, Lorr \& Droppleman, 1971). The internal consistency reliability 173 for POMS scales is 0.84 or greater (Spielberger, 1972).

174

175 Ethical aspects

176 All participants were informed of the potential risks and benefits of the study and signed 177 an informed consent form. All experimental procedures were approved $\left(\mathrm{n}^{\circ} 2.259 .846\right)$ by the 178 University Human Research Ethics Committee and conformed to the principles outlined in the 179 Declaration of Helsinki.

180

181 Statistical analysis

182 Data were entered into an Excel spreadsheet (Microsoft Office 2016, USA) and imported 183 into Statistical Package for the Social Science (SPSS) version 23.0 (IBM Corp., Armonk, USA) 184 for statistical analysis. Data were presented as mean \pm standard deviation and absolute and 185 relative frequencies. To test the normality of the sample, we used the Kolmogorov-Smirnov test. 186 As no data about domains of the POMS profile followed a normal distribution, the comparison 187 between groups (RG vs. AG vs. RAG) was done using the Kruskal-Wallis test followed by 188 Dunn's post-test. Fisher's exact test was applied to evaluate the association between the presence 189 of OVT and group. A significance level of 5\% was set for all statistical procedures.

\section{RESULTS} presented scores above four (Table 3).

As mentioned in the methods, a decreased performance was considered in those volunteers who were located at the extreme right in at least two of the following three selfevaluated aspects: training (Figure 1A); performance (Figure 1B); and recovery (Figure 1C). In this context, only $2.7 \%, 15 \%$ and $18.4 \%$ of the RG $(\mathrm{n}=2)$, AG $(\mathrm{n}=3)$, and RAG $(\mathrm{n}=7)$, 
198 respectively, were considered to have decreased performance. The exact Fisher's test showed

199 that distribution frequency was significantly different between groups $(p=0.009)$.

200 Regarding the assessment of mood state by POMS, 67.5\%, 80.0\% and 60.5\% of the RG

201 ( $\mathrm{n}=50), \mathrm{AG}(\mathrm{n}=16)$, and RAG $(\mathrm{n}=23)$, respectively, were classified as absent of mood

202 disorders (Standard Graphic Iceberg - Figure 2). There were no statistical differences $(\mathrm{p}=0.82)$

203 in the total mood disorder among RG $(13.9 \pm 24.5)$, AG (10.3 \pm 25.1$)$ and RAG $(14.6 \pm 27.9)$

204 groups.

205

206

\section{DISCUSSION}

207

The primary aim of this study was to evaluate the risk of OVR and OVT (related to

208 physical/mental work stress) in physical education professionals. The results showed that the 209 sample did not present predisposing factors, signs and symptoms of OVR and OVT. In addition, we observed a low presence of performance impairment. However, it is noteworthy that workplaces - especially for professionals whose bodies are a working tool - can place workers at a higher risk of injuries, disabilities, morbidities, and mortality (Knoblauch \& Cassaro, 2017).

Our results are in line with Ackel-D'Elia et al. (2010), who assessed the prevalence of 214 predisposing factors, signs and symptoms of OVR and OVT in 413 members of 17 gyms in São

215 Paulo (Brazil). The authors found a low prevalence of signs and symptoms of OVR and OVT, 216 including among individuals classified as belong to a higher risk subgroup.

217 The findings of the present study do not support the initial hypothesis, that the high 218 weekly volume of exercise (that includes own training session and exercise performed 219 professionally), would put physical education professionals at a high risk of developing OVR 220 and/or OVT syndrome. In fact, when we compare the weekly amount of exercise performed by 221 volunteers evaluated (5.1 \pm 0.9 hours) with that recommended by scientific societies, such as the 222 American College of Sports Medicine (ACSM) (Garber et al., 2011), we found that the weekly 223 volume of exercise is greater than recommended for the maintenance and development of 224 cardiorespiratory and neuromuscular fitness (Garber et al., 2011). The ACSM recommends that 225 individuals should engage in a moderate-intensity program for at least 30 minutes a day for five 226 or more days a week, totalizing a minimum of 150 minutes (2.5 hours) per week or perform an 227 intense training for at least 20 minutes a day for three or more days a week, totalizing a minimum 228 of 75 minutes (1.25 hours) per week (Garber et al., 2011). 
230 minutes) (Garber et al., 2011), the assessed volunteers trained more than twice the recommended

231 time/volume ( 400 minutes). However, when the weekly training volume of the sample is

232 compared with that of high-level athletes, 25-38 hours/week (Woods et al., 2017), it might be

233 considered low. In this regard, the findings of the present study appear consistent; that is, they

234 show an absence of predisposing factors, signs and symptoms of OVR and OVT in physical

235 education professionals. Even if we evaluate only the AG, the average weekly exercise of the

236 participants in this group is around 13 hours/week, also very distant from that found for 237 professional athletes.

238 Another variable related to the development of OVR and OVT is training intensity 239 (Purvis, Gonsalves \& Deuster, 2010). In the present study, with regard to training intensity 240 (question 14), $80(60.6 \%)$ of the 132 subjects reported that their training intensity was at least as 241 a little heavy. Many authors advocate that high-intensity exercise is necessary to evoke 242 physiological adaptations, and consequently to improve physical performance (Rogero, Mendes 243 \& Tirapegui, 2005; Bosquet et al., 2007). However, coaches should be aware of training load and 244 fatigue-related parameters in order to avoid OVR symptoms. In this context, it is clear that 245 training stimulus must be accompanied by adequate periods of recovery and a proper nutrition 246 and hydration (Rogero, Mendes \& Tirapegui, 2005; Bosquet et al., 2007).

Regarding recovery (question 16), 120 (90.9\%) reported a 'reasonable', 'good', 'very good' or 'very, very good' recovery. Therefore, even though the training intensity was 'a little heavy' for more than half of the volunteers, they reported an adequate recovery. As a result of a fairly heavy training and a considerable recovery, $91.6 \%(n=121)$ of the volunteers achieved at least regular performance.

Sleep disorders, occupational hazards, injuries and illnesses could impact professional and worker overall health (Kalliny \& McKenzie, 2017). Sportsmen and women with OVR and OVT usually reported sleep disorders (Winsley \& Matos, 2010). In this regard, the participants of the present study can be considered as having no sleep disorders, with the score of three groups showing an average below 3.0. A similar pattern was found for groups of questions that assessed external obligations to training, nutritional factors, hydration pattern, changes in appetite, weight loss, respiratory tract infections, excessive sweating, monotony, fatigue and motivation in relation to training. Particularly, in relation to nutritional factors, it has been 
260 suggested that, to ensure a more efficient replacement of energy stocks, especially muscle

261 glycogen, the post-workout meal should be eaten in the first hours of post-exercise recovery

262 (Beelen et al., 2010). Of the 132 volunteers evaluated, 90.9\% $(n=120)$ ate within two hours after 263 the training session.

264 Regarding monotony, we found that RG, AG and RAG showed low tiredness and 265 monotony in relation to training (scores lower than 3.0). This suggests that monotony was not 266 singled out as a factor that interferes in the training sessions for the volunteers. This data 267 combined with the results of training intensity, recovery and performance suggest that the 268 training carried out by volunteers was adequate. Considering that the volunteers are physical 269 education professionals, it is reasonable to assume that they had current and scientifically relevant information about exercise prescription and training planning.

Finally, regarding mood, 64.4\% $(\mathrm{n}=89)$ volunteers had an absence of signs and

272 symptoms of mood disorders (positive iceberg), while 32.6\% $(n=43)$ had an outside graphic

273 pattern or inverted/negative iceberg. Despite the relatively high number of individuals with 274 altered mood state, it seems prudent to not associate this fact to the characteristics of the training, 275 but possibly to psychosocial stressors related to work/modern life, since the RG, AG and RAG $276 \mathrm{had}$ an average score close to 4.0 in the group of questions related to the work activity and/or 277 study (one of the highest scores among those evaluated).

278

279

\section{Study limitations}

Firstly, the volunteers did not undergo biochemical (creatine kinase, testosterone, and cortisol) and physiological (heart rate variability and oxygen uptake) analysis. Such analysis could provide valuable information about the physiological status of volunteers, since several studies have demonstrated that these biochemical and physiological measures are changed in sportsmen and women with OVT (Halson et al., 2003; Silva, Santhiago \& Gobatto, 2006; Cadegiani \& Kater, 2017a,b). Secondly, the volunteers were not submitted to objective tests to evaluate their performance, such as a cardiorespiratory exercise test. Thirdly, the present study cannot differentiate the states of OVR and OVT. Fourthly, as for all studies employing questionnaires, the present results rely on the honesty and level of recall of respondents. Nevertheless, we believe that these limitations do not prevent the study's conclusions from being drawn. 


\section{CONCLUSION}

293 Despite the relatively high-volume work/training performed by the physical education

294 professionals surveyed, we can conclude that they did not have predisposing factors, signs and 295 symptoms of OVR and OVT. Additionally, no differences between RG, AG and RAG were 296 identified.

297

298

299

300

301

302

\section{ACKNOWLEDGEMENTS}

303

We would like to thank the participants for their effort and commitment to the research

304 project.

305

306

307

308

309

\section{REFERENCES}

Ackel-D'Elia C, Vancini RL, Castelo A, Nouailhetas VLA, Silva AC da. 2010. Absence of the predisposing factors and signs and symptoms usually associated with overreaching and overtraining in physical fitness centers. Clinics 65:1161-1166.

Bausewein C, Farquhar M, Booth S, Gysels M, Higginson IJ. 2007. Measurement of breathlessness in advanced disease: A systematic review. Respiratory Medicine 101:399410. DOI: 10.1016/J.RMED.2006.07.003.

Beelen M, Burke LM, Gibala MJ, van Loon LJC. 2010. Nutritional strategies to promote postexercise recovery. International Journal of Sport Nutrition and Exercise Metabolism 20:515-532.

Bosquet L, Montpetit J, Arvisais D, Mujika I. 2007. Effects of tapering on performance. Medicine \& Science in Sports \& Exercise 39:1358-1365.

Brazil. 1998. Lei n. 9.696, de 10 de setembro de 1998. Available at: http://www.camara.gov.br/sileg/integras/104896.pdf.

321 Cadegiani FA., Kater CE. 2017a. Hormonal aspects of overtraining syndrome: a systematic 
322

323

324

325

326

327

328

329

330

331

332

333

334

335

336

337

338

339

340

341

342

343

344

345

346

347

348

349

350

351

352

review. BMC Sports Science, Medicine and Rehabilitation 9:14. DOI: 10.1186/s13102-0170079-8.

Cadegiani FA., Kater CE. 2017b. Growth hormone (GH) and prolactin responses to a nonexercise stress test in athletes with overtraining syndrome: results from the Endocrine and metabolic Responses on Overtraining Syndrome (EROS) — EROS-STRESS. Journal of Science and Medicine in Sport. DOI: 10.1016/j.jsams.2017.10.033.

Carfagno DG, Hendrix JC. 2014. Overtraining syndrome in the athlete. Current Sports Medicine Reports 13:45-51. DOI: 10.1249/JSR.0000000000000027.

da Silva FIC, Santos AML, Araújo DME. 2005. Perfil profissional do personal trainer atuante em academias de Teresina-PI. Revista Brasileira de Prescrição e Fisiologia do Exercício 10:634-644.

Elliott MCCW, Wagner PP, Chiu L. 2007. Power athletes and distance training: physiological and biomechanical rationale for change. Sports medicine (Auckland, N.Z.) 37:47-57. DOI: 10.2165/00007256-200737010-00004.

Faul F, Erdfelder E, Buchner A, Lang A. 2009. Statistical power analyses using G*Power 3.1: Tests for correlation and regression analyses. Behavior Research Methods 41:1149-1160.

Fletcher D, Scott M. 2010. Psychological stress in sports coaches: A review of concepts, research, and practice. Journal of Sports Sciences 28:127-137. DOI: 10.1080/02640410903406208.

Fry RW, Morton AR, Keast D. 1991. Overtraining in athletes. An update. Sports Medicine $12: 32-65$.

Garber CE, Blissmer B, Deschenes MR, Franklin BA, Lamonte MJ, Lee I-M, Nieman DC, Swain DP. 2011. Quantity and quality of exercise for developing and maintaining cardiorespiratory, musculoskeletal, and neuromotor fitness in apparently healthy adults. Medicine \& Science in Sports \& Exercise 43:1334-1359.

Halson SL., Lancaster GI., Jeukendrup AE., Gleeson M. 2003. Immunological responses to overreaching in cyclists. Medicine \& Science in Sports \& Exercise 35:854-861.

Hjälm S, Kenttä G, Hassménan P, Gustafsson H. 2007. Burnout among elite soccer coaches. Journal of Sport Behavior 30:415-427.

Issurin VB. 2010. New horizons for the methodology and physiology of training periodization. Sports Medicine 40:189-206. 
353 Jones CM, Tenenbaum G. 2009. Adjustment Disorder: a new way of conceptualizing the

354

355

356

357

358

359

360

361

362

363

364

365

366

367

368

369

370

371

372

373

374

375

376

377

378

379

380

381

382

383

overtraining syndrome. International Review of Sport and Exercise Psychology 2:181-197.

Juniper EF, Guyatt GH, Jaeschke R. 1995. How to develop and validate a new quality of life instrument. In: Spilker B. Quality of life assessment in clinical trials. New York: Raven Press.

Kalliny M, McKenzie JG. 2017. Occupational health and sleep issues in underserved populations. Primary Care 44:e73-e97. DOI: 10.1016/j.pop.2016.09.010.

Knoblauch DK, Cassaro S. 2017. Workers Compensation.

Kreher JB, Schwartz JB. 2012. Overtraining syndrome: a practical guide. Sports Health 4:12838. DOI: $10.1177 / 1941738111434406$.

Kuipers H. 1998. Training and overtraining: an introduction. Medicine and Science in Sports and Exercise 30:1137-1139.

Lehmann M, Foster C, Keul J. 1993. Overtraining in endurance athletes: a brief review. Medicine and Science in Sports and Exercise 25:854-862.

Lemyre PN, Roberts GC, Stray-Gundersen J. 2007. Motivation, overtraining, and burnout: Can self-determined motivation predict overtraining and burnout in elite athletes? European Journal of Sport Science 7:115-126.

Mazerolle SM, Pitney WA, Casa DJ, Pagnotta KD. 2011. Assessing strategies to manage work and life balance of athletic trainers working in the national collegiate athletic association division I setting. Journal of Athletic Training 46:194-205. DOI: 10.4085/1062-605046.2.194.

McNair DM, Lorr M, Droppleman LF. 1971. Manual for the profile of mood states. San Diego Calif: Educational and Industrial Testing Service.

Meeusen R, Duclos M, Foster C, Fry A, Gleeson M, Nieman D, Raglin J, Rietjens G, Steinacker J, Urhausen A. 2013. Prevention, diagnosis, and treatment of the overtraining syndrome: Joint consensus statement of the european college of sport science and the American College of Sports Medicine. Medicine and Science in Sports and Exercise 45:186-205.

Morgan WP, Brown DR, Raglin JS, O’Connor PJ, Ellickson KA. 1987. Psychological monitoring of overtraining and staleness. British Journal of Sports Medicine 21:107-14.

Morgan WP, Costill DL, Flynn MG, Raglin JS, O’Connor PJ. 1988. Mood disturbance following increased training in swimmers. Medicine and Science in Sports and Exercise 20:408-14. 
384 Purvis D, Gonsalves S, Deuster PA. 2010. Physiological and psychological fatigue in extreme

385

386

387

388

389

390

391

392

393

394

395

396

397

398

399

400

401

402

403

404

405

406

407

408

409

410

411 Figure 2. Graphic POMS profile of resistance training group (RG), aerobic training group (AG),

412 and resistance and aerobic training group (RAG). 


\section{Table $\mathbf{1}$ (on next page)}

Characteristics of the professional groups.

aStatistically significant difference from AG ( $p<0.05$, Kruskal-Wallis test followed by test of Dunn). Values are presented as mean \pm standard deviation. RG: resistance group. AG: aerobic group. RAG: resistance and aerobic group. 
Table 1. Characteristics of the professional groups

\begin{tabular}{lllll}
\hline & $\begin{array}{l}\mathrm{RG} \\
(\mathrm{n}=74)\end{array}$ & $\begin{array}{l}\text { AG } \\
(\mathrm{n}=20)\end{array}$ & $\begin{array}{l}\text { RAG } \\
(\mathrm{n}=38)\end{array}$ & $\begin{array}{l}\text { Total } \\
(\mathrm{n}=132)\end{array}$ \\
\hline Age (years) & $27.0 \pm 6.0$ & $27.2 \pm 6.2$ & $27.3 \pm 6.1$ & $27.1 \pm 6.0$ \\
\hline Body mass $(\mathrm{kg})$ & $73.3 \pm 13.7$ & $74.2 \pm 14.1$ & $73.8 \pm 14.1$ & $73.6 \pm 13.8$ \\
\hline Height $(\mathrm{cm})$ & $171.5 \pm 8.9$ & $171.1 \pm 9.2$ & $171.4 \pm 9.1$ & $171.4 \pm 9.1$ \\
\hline Body mass index $\left(\mathrm{m} / \mathrm{kg}^{2}\right)$ & $24.5 \pm 3.9$ & $24.9 \pm 3.9$ & $24.7 \pm 3.9$ & $24.6 \pm 3.7$ \\
\hline Training session duration (hours) & $1.0 \pm 0.0^{\mathrm{a}}$ & $2.3 \pm 2.0$ & $1.3 \pm 0.9^{\mathrm{a}}$ & $1.3 \pm 1$ \\
\hline Weekly training frequency (days) & $5.0 \pm 0.9^{\mathrm{a}}$ & $5.6 \pm 0.9$ & $5.0 \pm 1$ & $5.1 \pm 0.9$ \\
\hline Training experience (months) & $57.7 \pm 71.8$ & $70.5 \pm 68.7$ & $36.4 \pm 4.3$ & $53.5 \pm 65.0$ \\
\hline Hazards of physical training & $28.4 \%$ & $60 \%$ & $42.1 \%$ & $37.1 \%$ \\
\hline Lasting more than 15 days & $12.2 \%$ & $25 \%$ & $23.7 \%$ & $16.7 \%$ \\
\hline
\end{tabular}

${ }^{\text {a}}$ Statistically significant difference from AG ( $\mathrm{p}<0.05$, Kruskal-Wallis test followed by test of

Dunn). Values are presented as mean \pm standard deviation. RG: resistance group. AG: aerobic group. RAG: resistance and aerobic group. 


\section{Table 2 (on next page)}

Groups of questions used to assess the OVR and OVT predisposing factors, signs and symptoms.

Note: Questions 9, 10 and 11 refer to self-evaluation of training, performance and recovery and have not been computed. 
Table 2. Groups of questions used to assess the OVR and OVT predisposing factors, signs and symptoms.

\begin{tabular}{lll}
\hline Question Group & \multicolumn{1}{c}{ Predisposing factors } & Questions \\
\hline Group 1 & Work activity and/or study & $1-5$ \\
\hline Group 2 & Non-training related problems & 30 and 31 \\
\hline Group 3 & Training motivation & $18-20$ \\
\hline Group 4 & Recovery pattern & $12-15$ \\
\hline Group 5 & Nutritional pattern & $21-25$ \\
\hline Group 6 & Hydration pattern & $26-29$ \\
\hline \multicolumn{1}{c}{ Signs and symptoms } \\
\hline Group 7 & Sleep patterns $\quad$ Previous injuries & $33-37$ \\
\hline Group 8 & Appetite pattern changes, weight loss, superior respiratory \\
\hline Group 9 & tract infections, and excessive sweating & 32 \\
\hline & Training monotony, motivation and tiredness \\
\hline Group 10 & Note: Questions & 9, 10 and 11 refer to self-evaluation of training, performance and recovery \\
and have not been computed. & $6-8,16$ and 17 \\
\hline
\end{tabular}




\section{Table 3(on next page)}

Predisposing factors, signs, and symptoms of OVR and OVT between professional groups.

SD: standard deviation. SRTI: superior respiratory tract infection. RG: resistance group. AG: aerobic group. RAG: resistance and aerobic group. 
Table 3. Predisposing factors, signs, and symptoms of OVR and OVT between professional groups.

\begin{tabular}{|c|c|c|c|c|c|c|}
\hline \multicolumn{2}{|c|}{ Question group (1 to 10) } & $\begin{array}{c}\mathrm{n}^{\mathrm{o}} \text { of } \\
\text { questions }\end{array}$ & RG & $\mathrm{AG}$ & RAG & $\begin{array}{c}\text { Total } \\
\text { average }\end{array}$ \\
\hline \multicolumn{7}{|c|}{ Predisposing factors } \\
\hline 1 & Work activity and/or study & 5 & 3.4 & 3.5 & 3.6 & 3.5 \\
\hline 2 & $\begin{array}{l}\text { Non-training-related } \\
\text { problems }\end{array}$ & 2 & 2.3 & 2.1 & 2.8 & 2.4 \\
\hline 3 & Training motivation & 3 & 3.5 & 3.4 & 3.8 & 3.6 \\
\hline 4 & Recovery pattern & 4 & 3.5 & 3.2 & 3.0 & 3.3 \\
\hline 5 & Nutritional pattern & 5 & 2.0 & 1.9 & 1.9 & 2.0 \\
\hline 6 & Hydration pattern & 4 & 2.1 & 2.2 & 2.1 & 1.8 \\
\hline \multicolumn{7}{|c|}{ Signs and symptoms } \\
\hline 7 & Sleep pattern & 5 & 2.2 & 2.4 & 2.3 & 2.2 \\
\hline 8 & Previous injuries & 1 & 2.4 & 3.8 & 3.6 & 2.9 \\
\hline 9 & $\begin{array}{l}\text { Appetite pattern changes, } \\
\text { weight loss, SRTI and } \\
\text { excessive sweating }\end{array}$ & 5 & 1.5 & 1.7 & 1.6 & 1.5 \\
\hline 10 & $\begin{array}{l}\text { Training monotony, } \\
\text { motivation and tiredness }\end{array}$ & 5 & 2.4 & 2.7 & 2.6 & 2.5 \\
\hline Mean \pm & & & $2.5 \pm 0.7$ & $2.7 \pm 0.7$ & $2.7 \pm 0.8$ & $2.6 \pm 0.7$ \\
\hline
\end{tabular}

SD: standard deviation. SRTI: superior respiratory tract infection. RG: resistance group. AG: aerobic group. RAG: resistance and aerobic group. 
Figure 1

Self-evaluation of the training (A), performance (B), and recovery (C) of the professionals according to the groups. RG: resistance training group; AG: aerobic training group; RAG: resistance and aerobic training group. 


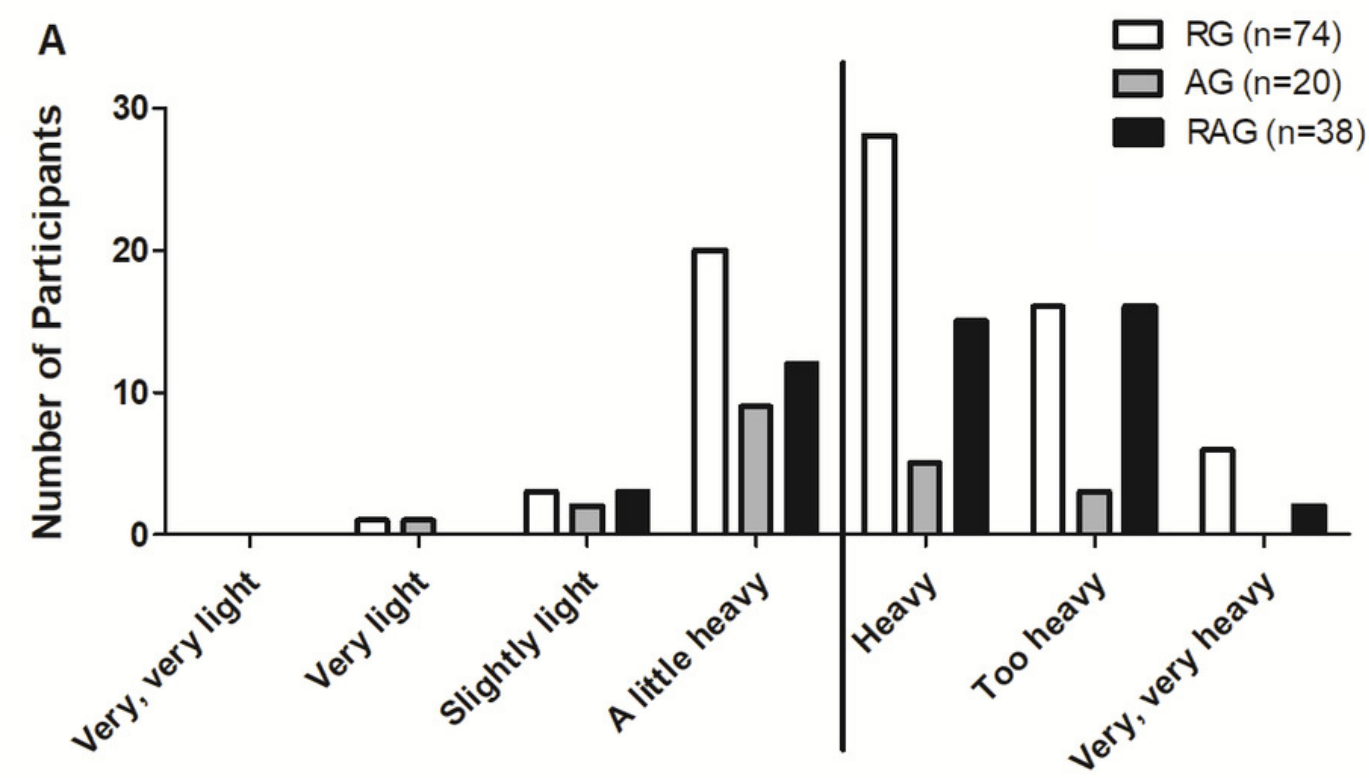

B

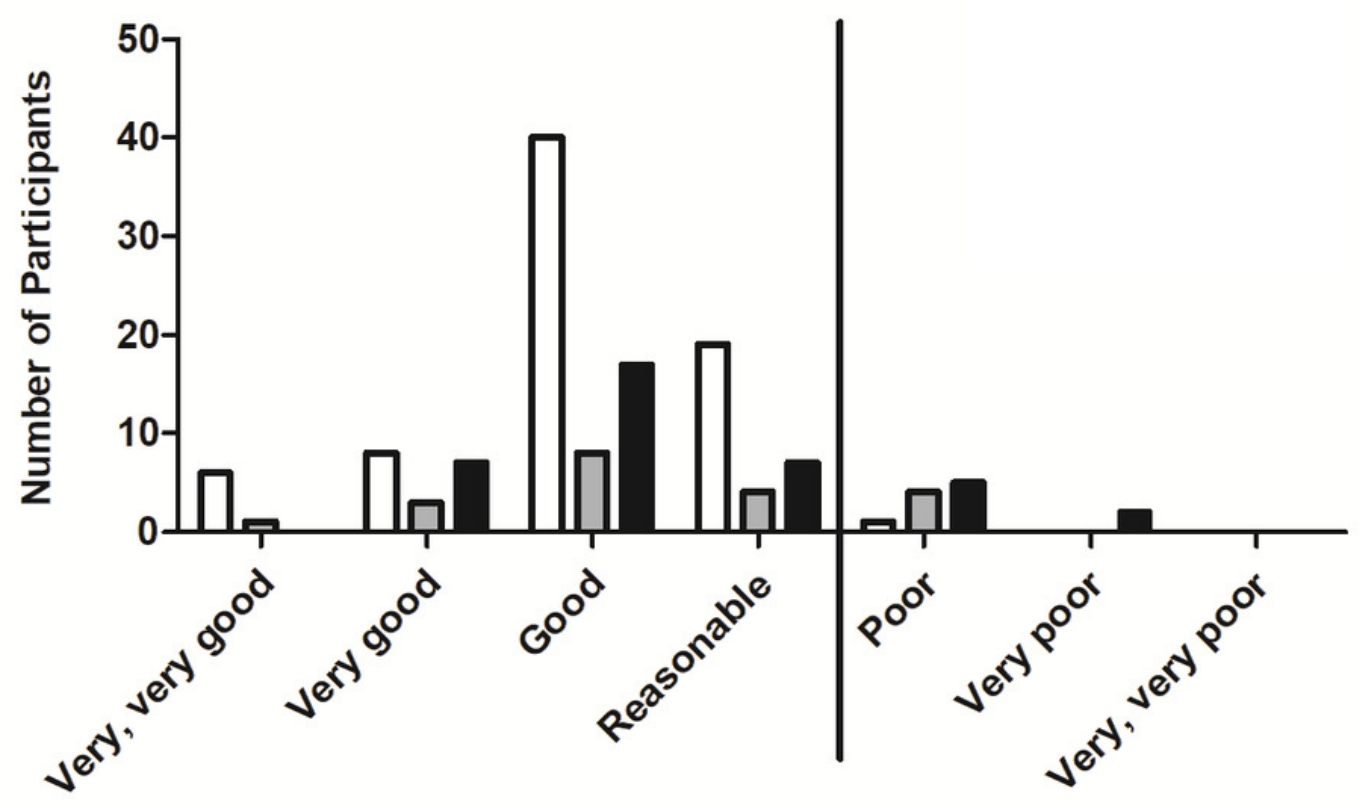

C

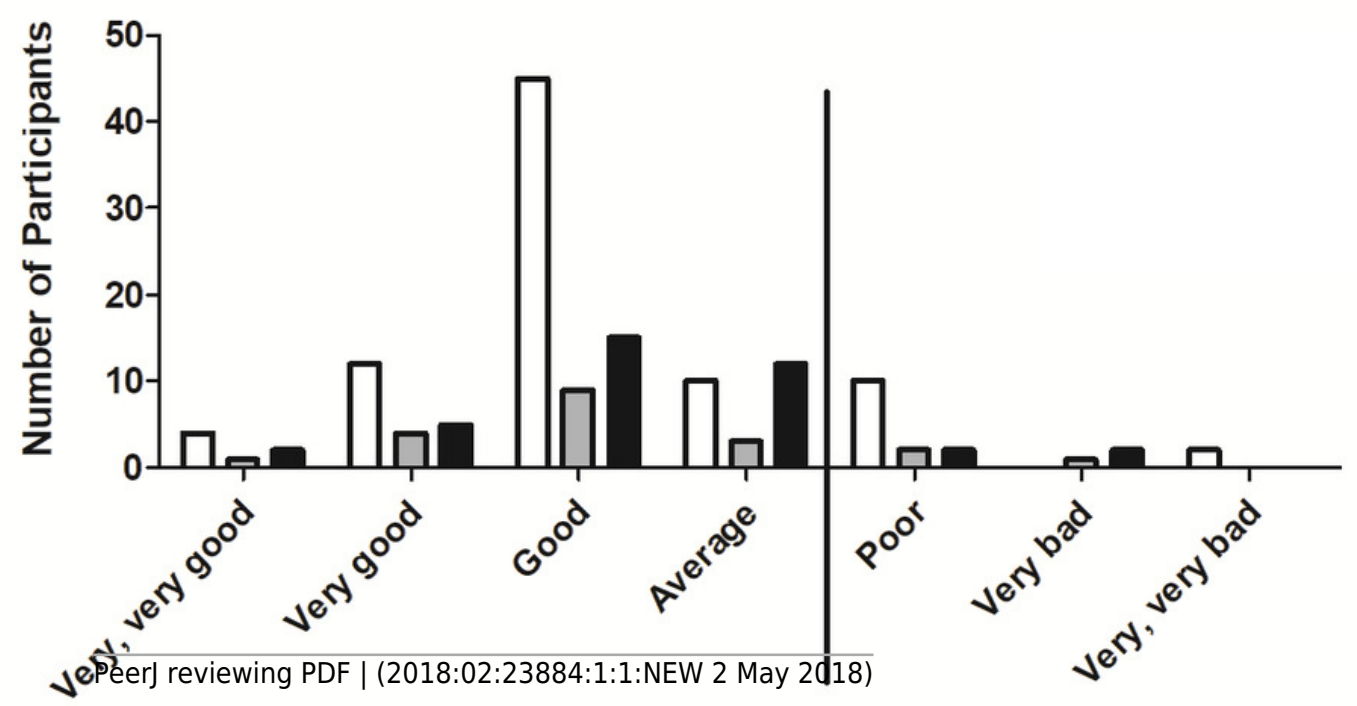


Figure 2

Graphic POMS profile of resistance training group (RG), aerobic training group (AG), and resistance and aerobic training group (RAG).

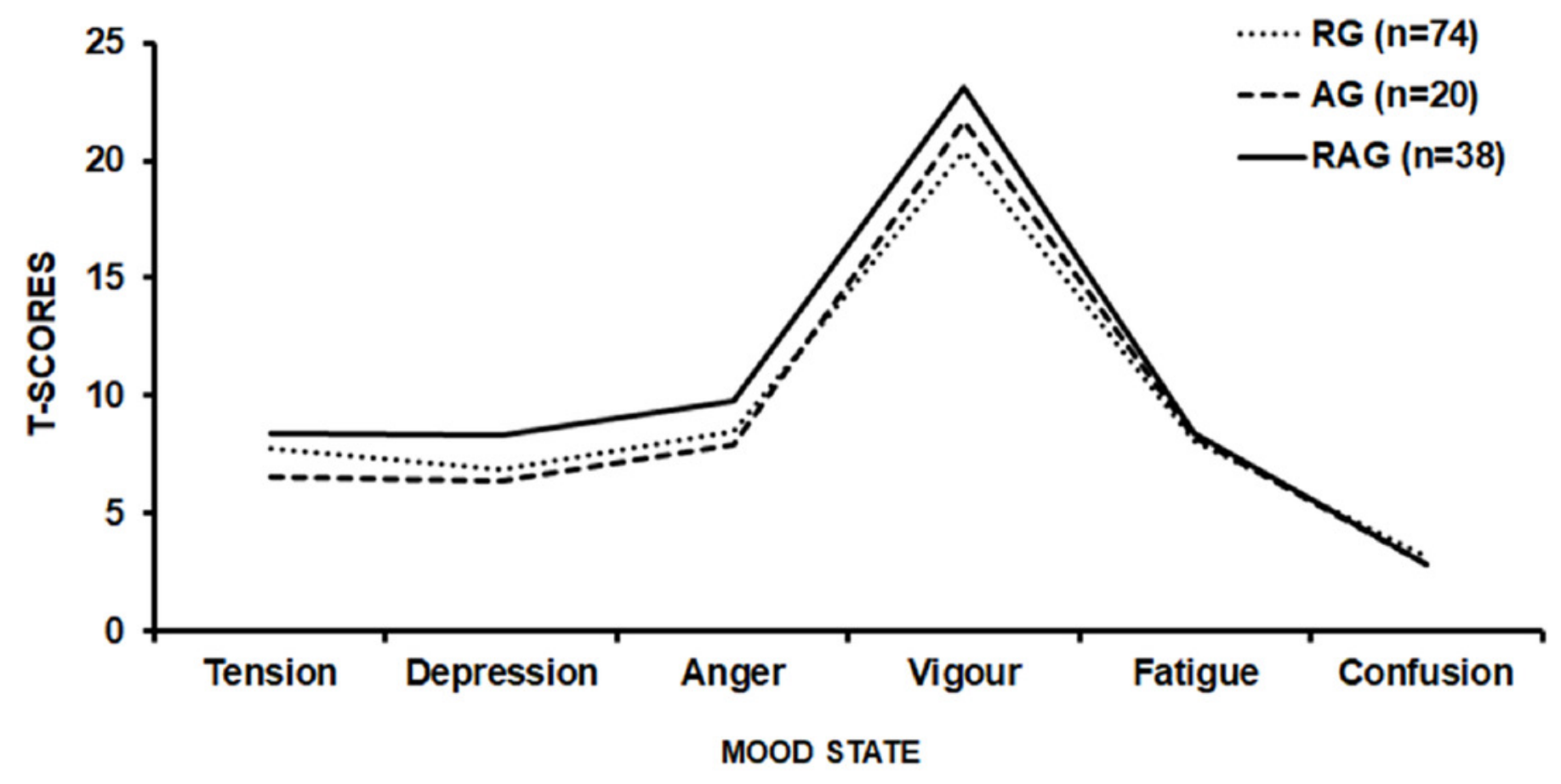

